\title{
ARE THERE MORE THAN TWO SELF-INCOMPATIBILITY LOCI IN THE GRASSES?
}

\author{
CAROLYN R. LEACH \\ Department of Genetics, University of Adelaide, South Australia 5001.
}

Received 18.viii.83

The genetic control of self-incompatibility has been investigated in a number of members of the Gramineae (table 1). The majority of these studies have revealed that the incompatibility system is controlled by two multi-allelic loci with gametophytic determination of pollen behaviour.

TABLE 1

Incompatibility systems identified in grass species

\begin{tabular}{|c|c|c|}
\hline Species & Two locus system & Other system \\
\hline Secale cereale & Lundqvist $(1954,1956)$ & \\
\hline Festuca pratensis & Lundqvist $(1955,1961 a)$ & \\
\hline Phalaris coerulescens & Hayman (1956) & \\
\hline Hordeum bulbosum & Lundqvist (1962) & \\
\hline Dactylis aschersoniana & Lundqvist (1965) & \\
\hline Briza media & Murray (1964) & \\
\hline B. spicata & & Murray (1979) \\
\hline Lolium perenne & $\begin{array}{l}\text { Cornish, Hayward \& } \\
\text { Lawrence (1979) }\end{array}$ & $\begin{array}{l}\text { Hayward \& Wright (1971) } \\
\text { Spoor }(1976) \\
\text { McCraw \& Spoor }(1983 b)\end{array}$ \\
\hline L. multiflorum & Fearon, Hayward \& & Hay (1978) \\
\hline & Lawrence (1983) & McCraw \& Spoor $(1983 a)$ \\
\hline L. rigidum & & McCraw \& Spoor $(1983 a)$ \\
\hline
\end{tabular}

Apart from the case (Murray, 1979) all exceptions have been found in Lolium species. However, despite claims to the contrary, careful examination of all these reports reveals that the data are not satisfactorily explained by considering three or even four loci though gametophytic determination of pollen behaviour has always been shown.

In a two locus system sixteen different types of progeny arise when the parents of a cross are heterozygous for different alleles at each locus, e.g., $S_{1.2} Z_{1 \cdot 2} \times S_{3.4} Z_{3.4}$. With the exception of the families considered by Hayward and Wright (1971), all Lolium progenies described which gave results inconsistent with a two locus system had at least 17 different incompatibility types. Indeed, no progeny cited ever had two members with the same incompatibility genotypes as detected by the results of in vitro pollination tests (Lundqvist, 1961b).

A three locus system where the parents of the cross are heterozygous for different alleles at each locus, e.g., $S_{1.2}^{\prime} S_{1 \cdot 2} Z_{1 \cdot 2} \times S_{3.4}^{\prime} S_{3 \cdot 4} Z_{3 \cdot 4}$, leads to 64 different types of progeny. However, in a progeny of say, 28, the probability that all 28 will be of different genotypes is $9 \cdot 1168 \times 10^{-4}$ (Feller, 1957, vol. 1, p. 30). 
The probabilities of obtaining all members of the progeny of different incompatibility status for the Lolium species in which a three locus system has been claimed are shown in table 2 . Further, since all sets of observations are independent, the data may be grouped by species (table 3 ).

The same analysis can be applied to the data considering a four locus system which leads to a maximum of 256 different types of progeny and the probabilities are shown in tables 2 and 3.

TABLE 2

Likelihood of obtaining all members of a progeny of different incompatibility status under (a) a three locus system, (b) a four locus system

\begin{tabular}{llccc}
\hline \multicolumn{1}{c}{ Author } & \multicolumn{1}{c}{ Species } & Family size & $\begin{array}{c}\text { Probability } \\
\text { (a) }\end{array}$ & (b) \\
\hline Spoor (1976) & L. perenne & 28 & 0.00091 & 0.2160 \\
Hay (1978) & L. multiflorum & 26 & 0.00266 & 0.2688 \\
McCraw \& Spoor (1983a) & L. rigidum & 25 & 0.00436 & 0.2979 \\
& L. rigidum & 25 & 0.00436 & 0.2979 \\
& L. rigidum & 27 & 0.00158 & 0.2415 \\
& L. multiflorum & 27 & 0.00158 & 0.2415 \\
McCraw \& Spoor (1983b) & L. multiflorum & 17 & 0.09676 & 0.5810 \\
& L. perenne & 23 & 0.01089 & 0.3611 \\
\hline
\end{tabular}

The data from Hayward \& Wright (1971) are not considered as no claim that a three locus model satisfied these results was made.

TABLE 3

Pooling the results for each Lolium species in table 2

(a)

\begin{tabular}{llll}
\hline L. perenne & $0.00091 \times 0.01089$ & $=9.90 \times 10^{-6}$ & 0.0780 \\
L. multiflorum & $0.00266 \times 0.00158 \times 0.09676$ & $=4.07 \times 10^{-7}$ & 0.0377 \\
L. rigidum & $0.00436 \times 0.00436 \times 0.00158$ & $=3.00 \times 10^{-8}$ & 0.0214 \\
\hline
\end{tabular}

Thus, as only one of the reported families has a probability of more than 5 per cent of occurring under a three locus system, such a system does not provide a satisfactory explanation for the results. A four locus model seems acceptable for $L$. perenne. However, alternative explanations for these results being at variance with those of Cornish et al., (1979) for $L$. perenne and Fearon et al., (1983) for $L$. multiflorum would appear to lie in the way in which Spoor (1976), Hay (1978) and McCraw and Spoor $(1983 a$ and $b$ ) have interpreted the results of in vitro pollination tests. For example, McCraw and Spoor (1983b) described some "self-compatible" plants as follows: "More than half (11 out of 23) of the plants were self-compatible when pollinated in vitro. When these plants were allowed to self-pollinate in vivo, two seeds were produced by plant 5 while the other ten plants did not set any seed". If in vitro pollination tests scored by these workers gave misleading results about the true self-incompatibility status of these plants then the interpretation of all their in vitro tests must be regarded as problematic. 
In addition McCraw and Spoor (1983a) present tables showing compatible pollinations in which, in some cases, plants which are reciprocally self-incompatible are classified as being different when they differ in only 2 or 3 of more than 90 pollination tests and in others, e.g., fig. 4 (loc. cit.) where data in the diallel tables seem too meagre for any realistic conclusions to be drawn with respect to the similarity of the plants.

Thus a critical analysis of the conflicting results leads to acceptance of the accuracy of the results of Cornish et al., (1979) for L. perenne and Fearon et al., (1983) for L. multiflorum which indicate a two locus, multiallelic gametophytic system of incompatibility in these species, especially as the results of their pollination tests are well substantiated by extensive data on seed set (Cornish et al., 1980; Fearon et al., 1983).

Acknowledgements. I would like to thank Dr O. Mayo for his help and encouragement in the preparation of this manuscript.

\section{REFERENCES}

CORNISH, M. A., HAYWARD, M. D. AND LAWRENCE, M. J. 1979. Self-incompatibility in ryegrass. I. Genetic control in diploid Lolium perenne L. Heredity, 43, 95-106.

CORNISH, M. A., HAYWARD, M. D. AND LAWRENCE, M. J. 1980. Self-incompatibility in ryegrass. IV. Seed set in diploid Lolium perenne L. Heredity, 44, 333-340.

FEARON, C. H., HAYWARD, M. D. AND LAWRENCE, M. J. 1983. Self-incompatibility in ryegrass. V. Genetic control, linkage and seed set in diploid Lolium multiflorum Lam. Heredity, 50, 35-45.

FELler, w. 1957. An Introduction to Probability Theory and its Applications, vol. 1, 2nd edition. John Wiley and Sons Inc., New York/London.

HAY, J. M. 1978. Incompatibility in Lolium multiflorum. Incompat. Newsletter, 10, 134-136.

HAYMAN, D. L. 1956. The genetical control of incompatibility in Phalaris coerulescens Desf. Aust. J. Biol. Sci., 9, 321-331.

HAYWARD, M. D. AND WRIGHT, A. J. 1971. The genetic control of incompatibility in Lolium perenne L. Genetica, 42, 414-421

LUNDOVIST, A. 1954. Studies on self-sterility in rye, Secale cereale L. Hereditas, 40, 278-294. LUNDOVIST, A. 1955. Genetics of self-incompatibility in Festuca pratensis. Hereditas, 41, 518-520.

LUNDQVIST, A. 1956. Self-imcompatibility in rye. I. Genetic control in the diploid. Hereditas, 42, 293-348.

LUNDQVIST, A. 1961 a. Self-incompatibility in Festuca pratensis Huds. Hereditas, 47, 542-562.

LUNDQVIST, A. 1961 b. A rapid method for the analysis of incompatibility in grasses. Hereditas, 47, 705-707.

LUNDQVIST, A. 1962, Self-incompatibility in diploid Hordeum bulbosum L. Hereditas, 48, 138-152.

LUNDQVIST, A. 1965. Self-incompatibility in Dactylis aschersoniana Graebn. Hereditas, 54, 70-87.

McCRAW, J. M. AND SPOOR, W. 1983a. Self-incompatibility in Lolium species. I. Lolium rigidum Gaud. and L. multifiorum L. Heredity, 50, 21-27.

McCRAW, J. M. AND SPOOR, W. 1983 b. Self-incompatibility in Lolium species. 2. Lolium perenne L. Heredity, 50, 29-33.

MURRAY, B. G. 1974. Bredding systems and floral biology in the genus Briza. Heredity, 33, 285-292.

MURRAY, B. G. 1979. The genetics of self-incompatibility in Briza spicata. Incompat. Newsletter, 11, 42-45.

SPOOR, w. 1976. Self-incompatibility in Lolium perenne L. Heredity, 37, 417-421. 